\title{
ABG Analysis and its Interpretation
}

\author{
Apsara $\mathbf{N}^{1}$, Nivedhitha $\mathrm{K}^{2}$, A Felicia Chitra ${ }^{3}$ and Manjubala Dash ${ }^{4 *}$ \\ ${ }^{1}$ Mother Theresa Post Graduate and Research Institute of Health Sciences, India \\ ${ }^{2}$ Associate professor, Department of MSN, Mother Theresa Post Graduate and Research Institute of Health Sciences, India \\ ${ }^{3}$ Professor cum Principal Department of MSN, Mother Theresa Post Graduate and Research Institute of Health Sciences, India \\ ${ }^{4}$ Professor cum HOD, Mother Theresa Post Graduate and Research Institute of Health Sciences, Puducherry, India \\ *Corresponding Author: Manjubala Dash, Professor cum HOD, Mother Theresa Post Graduate and Research Institute of Health Sciences, \\ Puducherry, India.
}

Received: August 29, 2019; Published: September 23, 2019

DOI: $10.31080 /$ ASPE.2019.02.0153

\begin{abstract}
Background: Blood consist of two components, the fluid part of blood or plasma that accounts for about 55\% of blood and the formed elements of blood or blood cells that constitutes about $45 \%$ of the total volume of blood. An arterial blood gas analysis (ABGA) is a blood test that is performed using blood from an artery. Arterial Blood Gas analysis is a frequently used tool for assessing arterial blood oxygenation. Physicians, registered nurses, and respiratory therapists are responsible for the accurate interpretation of ABG data as part of the evaluation and management of acutely and critically ill patients.

Aim: The study was designed to evaluate the knowledge of ABG analysis among Nursing officers in Emergency care units.

Subjects and Methods: A descriptive study was conducted among Nursing officers in selected Hospital at Puducherry. Sample size was 50, selected through purposive sampling. The approach used for the study was Quantitative approach and design was descriptive design. Researcher made questionnaire contained four sections i.e., demographic variables, questions related to normal values of ABG Analysis, Items on Technique of ABG sampling, and items on interpretation of ABG Results respectively.

Results: The major findings of the study, $2 \%$ had inadequate knowledge, $36 \%$ had moderate knowledge and $62 \%$ had adequate knowledge on ABG Analysis and its Interpretation.

Conclusion: The study revealed that most of the Nursing officers had Adequate knowledge regarding ABG Analysis. Hence the results of the study proves that the working experience in critical care units will improve the knowledge.

Keywords: Arterial Blood Gas Analysis; Knowledge; Nursing Officers; Emergency Units
\end{abstract}

\section{Introduction}

Blood consist of two components, the blood and plasma that accounts for about $55 \%$ of blood and the formed elements of blood or blood cells that constitutes about $45 \%$ of the total volume of blood. It plays a vital role in the body. Its various functions includes transportation, nutritive, respiratory, excretory, homeostatic maintenance of body temperature and storage function [1].

Arterial blood gas analysis is an essential part of diagnosing and managing a patient's oxygenation status and acid-base balance. The usefulness of this diagnostic tool is dependent on being able to correctly interpret the results. This self-learning packet will examine the components of an arterial blood gas, what each component represents and the interpretation of these values to determine the patient's condition and treatment.

An arterial blood gas analysis is very useful laboratory findings for critically ill patients with acid base imbalances. This interpre- tation shows the oxygenation and ventilation status. An arterial blood gas analysis (ABGA) is a blood test that is performed using blood from an artery. It involves puncturing an artery with a thin needle and heparinized syringe and drawing a small volume of blood (approximately $1 \mathrm{ml}$ ). The most common puncture site is the radial artery at the wrist, but sometimes the femoral artery in the groin or other sites are used. The blood can also be drawn from an arterial catheter. The test is used to determine the $\mathrm{pH}$ of the blood, the partial pressure of carbon dioxide and oxygen, and the bicarbonate level. Many blood gas analyzers will also report concentrations of lactate, hemoglobin, several electrolytes. In order to understand and interpret ABGs one has to have a clear knowledge regarding the nomenclature, physiology and types of acid base disorders. Disorders of acid base balance can complicate many disease states and occasionally the abnormality may be so severe as to be life threatening. Monitoring of ABGs is an essential part in the anesthetic management of the high-risk patients as well as in the care of 
critically ill patients in the ICU. An ABG is typically requested to determine the $\mathrm{pH}$ of the blood and the partial pressures of carbon dioxide (PaCO2) and oxygen (PaO2) within it. It is used to assess the effectiveness of gaseous exchange and ventilation, be it spontaneous or mechanical. Nurse as a primary care giver play an important role in early detection of high risk clients with acid-base imbalance in critical care units. The nurse collaborates in the administration of drug, oxygen therapy and mechanical ventilation when indicated. In extreme circumstances in which therapeutic compensation is required, the nurse should be knowledgeable about potential risks of this therapy and able to carefully monitor administration rates and therapeutic responses [2-14].

Critically ill patients are not confined to critical care departments. Every day, practitioners working in acute areas encounter arterial blood gas (ABG) results, which they may not necessarily be able to interpret. It is difficult to find time to develop knowledge. However, in light of guidance and policy documents, it is imperative that all nurses working in acute areas can interpret ABGs and ensure patients receive timely and appropriate care.

Patients being cared for in general clinical areas are becoming sicker and sicker patients require more complex care and treatment. As a consequence the accurate and timely interpretation of test results has become an essential skill for nurses to function effectively. However, many nurses find confusing in interpreting arterial blood gas (ABG) results as outside of the scope of their practice.

Due to the increase in patient dependency it is no longer unusual for nurses to be caring for patients who need frequent $A B G$ analysis. Nurses are often the first members of the health care team to see ABG results and an understanding of their significance and the ability to decide when medical staff needs to be informed is important. Errors like Acidosis and alkalosis occur in Intensive care units(ICUs).

Aim

- To assess the existing level of knowledge of ABG Analysis and its interpretation among Nursing officers.

- To find out the association between knowledge of nursing officers and their selected demographic variables.

\section{Methodology}

The quantitative research approach was found to be appropriate and research design was used in this study was descriptive study (non-experimental) and the research variables are knowledge of ABG Analysis among the nursing officers. The study was conducted in selected hospitals of puducherry. The nursing officers in all emergency care units come under the inclusion criteria were chosen as samples. The size of the samples consists of 50 nursing officers. The inclusion criteria of sample were Nursing officers in all emergency care units, Who are willing to participate in this study and who are present at the time of data collection period. The tool description was divided into four sections. Section A; consists of demographic variables which include age, sex, qualification, experience, no of years experience in emergency care units. Section B:consists of normal values of ABG analysis. Section C: consists of items on technique of $A B G$ Sampling. Section D; Items on interpretation of $\mathrm{ABG}$ Results. It contains questions, correct answer carries one mark and zero for the wrong answer. Data collection procedure includes prior permission from the concern authority. The study was done for one week period and data was collected from the nursing officers in all emergency care units at selected hospital of puducherry.

\section{Result}

The result describe that the majority of 34 subjects (68\%) were in the age group of 31-40 years. All the study subjects (50) were female. And most of the subject's (43) educational qualification was GNM. The nearly half 45 subjects were experienced for above 10 years and 3 subjects had 1-3 years of experience in emergency units. $32 \%$ of subjects were working in ICU during the period of data collection.

\begin{tabular}{|l|c|c|}
\hline \multicolumn{1}{|c|}{ Demographic variables } & Frequency & Percentage \\
\hline AGE & & \\
\hline 25-30 years & 4 & $8 \%$ \\
\hline 31-40 years & 34 & $68 \%$ \\
\hline $41-50$ years & 12 & $24 \%$ \\
\hline SEX & & \\
\hline Male & -- & $0 \%$ \\
\hline Female & 50 & $100 \%$ \\
\hline Educational qualification & & \\
\hline GNM & 43 & $86 \%$ \\
\hline B.Sc NURSING & 1 & $2 \%$ \\
\hline PBBSc & 6 & $12 \%$ \\
\hline M.Sc NURSING & -- & $0 \%$ \\
\hline Total professional experience & & \\
\hline 1-5 Years & -- & $0 \%$ \\
\hline 5-10 Years & 5 & $10 \%$ \\
\hline Above 10 Years & 45 & $90 \%$ \\
\hline $\begin{array}{l}\text { Duration of Experience inn } \\
\text { Emergency Unit }\end{array}$ & & \\
\hline 0-1 years & 10 & $20 \%$ \\
\hline 1-3 years & 3 & $6 \%$ \\
\hline Above 3 years & 37 & $74 \%$ \\
\hline $\begin{array}{l}\text { Area of experience in emer- } \\
\text { gency care unit }\end{array}$ & 14 & \\
\hline ICU & & $28 \%$ \\
\hline Emergency Ward & $16 \%$ \\
\hline Post Operative Ward & & \\
\hline Casualty & & \\
\hline & & \\
\hline
\end{tabular}

Table 1 
Regarding knowledge on ABG and its interpretation 31 (62\%) subjects had adequate level of knowledge and 18 (36\%) subjects had moderately adequate knowledge and $1(2 \%)$ had inadequate knowledge.

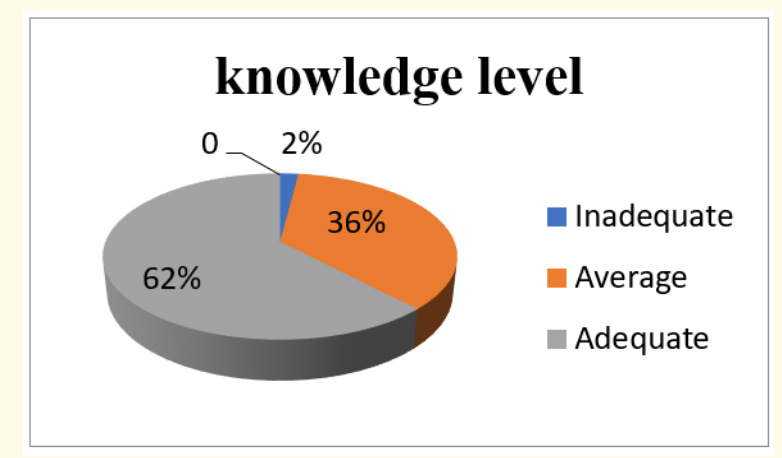

Figure

Further the association between the level of knowledge and demographic variables was done by the investigator. But the level of knowledge about ABG Analysis and its interpretation had not shown any statistically significant association with the selected demographic variables.

\section{Discussion}

The nurse as a professionalist should have sound knowledge on Blood chemistry because they are first person to notice all the health deviations happens to the patients. Since they working for $24 \times 7$ hours. 34 subjects (68\%) were in the age group of $31-40$ years. All the study subjects (50) were female. And most of the subject's (43) educational qualification was GNM. The nearly half 45 subjects were experienced for above 10 years and 3 subjects had 1-3 years of experience in emergency units. $32 \%$ of subjects were working in ICU. So here, the Demographic variable study results also says that all most all the nursing officers possess the knowledge on ABG Analysis and its interpretation that (31) had adequate level of knowledge, (18) had average of knowledge and except (1) had inadequate level of knowledge.

These finding were consistent with the study conducted by V. Hemavathy., et al. In Results reveals that out of 30 samples 4(13.3\%) had inadequate knowledge, 20 (66.7\%) had moderate knowledge and only $6(20 \%)$ had adequate knowledge ABG Analysis. In post test $4(13.3 \%)$ had moderate adequate knowledge and $26(86.7 \%)$ had adequate knowledge and none had inadequate knowledge about ABG Analysis.

The results of the present study was consistent with results of another study by K Padma., et al. regarding ABG Analysis and its interpretation among 30 staff nurses shows $4(13.3 \%)$ had A grade, $7(23.3 \%)$ had B + grade, 12(40\%) had B grade, 5(16.7\%) had C grade and $2(6.7 \%)$ had D grade knowledge and mean value was 19.0 and standard deviation was 3.5 in staff nurses.

\section{Conclusion}

The above study was undertaken to assess the knowledge on ABG Analysis and its interpretation among Nursing officers. If they are able to interpret correctly can prevent complications, keep away from errors and help in improving the condition of the patient. So the study motivates nursing officers in improving knowledge on $\mathrm{ABG}$ analysis and its interpretation and ultimately improve the patient care and quality of nursing care. It becomes vital for the nurses working in critical care departments should have additional knowledge on ABG Analysis and its interpretation in order to save the patients from developing quite lot of complications.

\section{Recommendations}

The study can be conducted with the large sample in different hospitals.

An Experimental study can be done with video assisted teaching and informational booklet method.

\section{Bibliography}

1. Annamma Jacob. Clinical nursing procedure the art of nursing practice, 1st edition: published by Jaypeebrothers medical publishers (P) ltd: New Delhi (2007).

2. Coggon JM. "Arterial blood gas analysis 1: understanding ABG reports". Nursing Times 104 (2008): 28-29.

3. Akashpreet Kaur. International Journal of Health Sciences and Research (2018): 182-188.

4. Khurana (I). Textbook of Anatomy and physiology for nurses and allied health science (2014): 35-37.

5. Colyar MR. Ambulatory care rocedures: Second edition: Published by F.A Davis company: USA (2004).

6. McGloin. Four-Step method of Interpreting Arterial Blood Gas Analysis. Nursing Times (2005): 23-24.

7. Polit and Beck. Textbook of nursing research: 18 edition (2008).

8. GP. "Interpretation of Arterial blood gas". Indian Journal of Critical care Medicine (2010): 57-64.

9. Basnett S. "Effectiveness of pocket reference on arterial blood gas analysis among the staff nurses working in critical care units". Manipal Journal of Nursing and Health Sciences (2016): $25-28$. 
10. NZ. "Knowledge of critical care nurses of Tehran's selected hospitals about Arterial blood gas interpretation". Iranian Journal of Cardiovascular Nursing (2014): 23.

11. SB. "Effectiveness of pocket reference on arterial blood gas analysis among the staff nurses working in critical care units". Manipal Journal of Nursing and Health Sciences (2016): 25-28.

12. Mohammed H. "Easy Blood Gas Analysis : Implications for Nursing". Egyptian Journal of Chest Disease and Tuberculosis (2006): 371-375.

13. David A. "Interpretation of ABGs". American Thoracic Society (2018): 25-26

14. Egyptian Journal of Chest Diseases and Tuberculosis. Easy Blood Gas Analysis: Implications For Nursing 65 (2016): 369376.

\section{Volume 2 Issue 10 October 2019}

(C) All rights are reserved by Manjubala Dash., et al. 